\title{
Depression among Physicians that are Mothers in Mexico: A Cross Sectional Study
}

Sandra Lopez-Leon ( $\nabla$ sandra.lopez@novartis.com )

https://orcid.org/0000-0001-7504-3441

Karen Rosales Mariscal

Doctors Hospital

Cipatli Ayuzo Del Valle

Hospital Mugureza

Luz Odette Villegas-Pichardo

Centro SUMA

Alejandra Huante Salceda

Hospital San Angel Inn

\section{Research note}

Keywords: depression, physicians, HAD-S, prevalence

Posted Date: September 12th, 2019

DOI: https://doi.org/10.21203/rs.2.14433/v1

License: (c) (1) This work is licensed under a Creative Commons Attribution 4.0 International License. Read Full License 


\section{Abstract}

OBJECTIVE : Common mental disorders are prevalent in medical doctors, especially in female. In Mexico, there are many studies showing that medical students and residents present a higher frequency of depression compared to the general population, however there are no studies in medical doctors at a later stage. A questionnaire was sent in an online forum for physicians that are mothers based in Mexico with the objective of estimating the point prevalence of depression among this group. The questionnaire included the Hospital and Anxiety Scale (HAD-S) which assess symptoms of depression. A cut-off score of $\geq 8$ or use of antidepressants was used to define depression. RESULTS : A total of 1170 physicians that are mothers were included in this study. The point prevalence of depression was $10.9 \%$. The group that had depression smoked more and took more sleeping pills that the group that did not present symptoms of depression. The point prevalence of symptoms of depression in this group of physician in Mexico was estimated to be of $10.9 \%$, which is similar to what is seen in the general population but lower than the estimates for medical interns and residents.

\section{Introduction}

Depression is characterized by persistent feeling of sadness, loss of interest, change in appetite, sleep disturbance, loss of energy, and neurocognitive dysfunction. Other symptoms include loss of confidence and self-esteem, inappropriate guilt, and thoughts of death and suicide [1].

Physicians have a higher risk of developing mental disorders such as depression compared to the general population [2]. Several factors have been proposed to explain this predisposition: a large patient to physician ratio, multiple on-call hours, insufficient sleep, grueling hours of lecture, difficulties with disclosure and financial burdens in form of student loans [3]. Women physicians have been seen to have a higher risk of depression compared to their male colleagues. Some sources of stress that are unique to or more prevalent amongst female professionals includes: minority status/discrimination, lack of role models and support, role strain, the dual career-couple and pregnancy/motherhood [4].

Depression is highly prevalent throughout the world and the prevalence has increased over time [5]. The prevalence is approximately two times greater in females compared to males [6]. The World Health Organization estimated a point prevalence of depression in the general population to be $1.9 \%$ for men and $3.2 \%$ for women [6]. However, other studies have shown higher estimates. For example, a nationally representative survey showed a point prevalence of $7 \%$ in the United States, and in Mexico $15 \%[7,8]$. These estimates vary depending on age, sex ratio and the diagnostic criteria used.

Studies have suggested that physicians have higher rated of depression when compared to the general population [7]. Concerning the prevalence of depression in physicians, most studies have focused on medical students, interns and medical residents. Mata et al 2015 conducted a meta-analysis with the objective of providing a summary estimate of depression among resident physicians. The overall pooled prevalence was of $28.8 \%(95 \% \mathrm{Cl} 25.3-32.5 \%)$. The prevalence of depression varies between studies, 
ranging from $20.9 \%$ to $43.2 \%$ depending on the instrument used [9]. In this meta-analysis there were only 2 studies included from Mexico $[10,11]$ that were cross-sectional. They both included less than 100 medical or surgical residents. One estimated the prevalence to be of $16.2 \%(95 \% \mathrm{Cl}$ 8.9-26.2) [10] and the other estimated a prevalence of $44.4 \%(95 \% \mathrm{Cl} 34-55.3)$ [11].

The objective of this study is to estimate the point prevalence of symptoms of depression in a large sample of physicians that are mothers with different specialties in Mexico.

\section{Methods}

Data for the analyses were obtained from a questionnaire launched in March 2017 in an online forum for Mexican women physicians who were mothers. Informed consent was requested at the beginning of the questionnaire, based on guidelines from www.who.int. This emphasized participation was anonymous and voluntary.

The questionnaire contained forced-choice and open-ended questions that asked respondents to express their views. We collected information on age, marital status, professional details, medication used, childbearing, health and well-being.

Symptoms of depression were assessed using the Depression subscale of the Hospital Anxiety Depression Scale (HADS-D) [12]. This scale is validated and reliable self-report measures of symptoms of depression. The HADS-D consists of 7 items with scores ranging from 0 to 21 . Higher scores indicate more symptoms of depression. A cut-off score of $\geq 8$ was used, indicating a possible major depression or clinical anxiety disorder. Depression was defined as a higher score of $\geq 8$ in the HADS scale or use of an antidepressant.

Point prevalence was calculated as the number of persons with symptoms of depression divided by the total number of participants multiplied by 100 . Confidence intervals were constructed using the exact Clopper-Pearson [13]. Categorical and continuous data were summarized by frequency and percentage, and mean and standard deviation (SD), respectively. Some answers were stratified by medical specialty. Statistical Analyses were conducted using the SAS System, version 9.3.

\section{Results}

A total of 1170 physicians that are mothers were included in this study. The mean age was 36.1 (SD 5.1), all were females and were mothers. A total of $6.2 \%$ had a score of $\geq 8$ in the HADs scale. The point estimate of depression was estimated to be of $10.9 \%$.

Table 1 shows that the individuals with depression smoked more (16.5\% vs $9 \%)$ and took more sleeping pills $(21.3 \%$ vs $3 \%)$ than the individuals that did not have depression. It was also observed that the individuals without depression did more exercise than the depressed individuals, although this estimate was not statistically significant $(38.3 \%$ vs $30.7 \%$ 
Table 1. General Characteristics of the population

\begin{tabular}{|l|l|l|l|l|}
\hline & $\begin{array}{l}\mathbf{N} \text { Total } \\
\mathbf{1 1 7 0}\end{array}$ & $\begin{array}{l}\text { No Depression } \\
(\mathbf{N = 1 0 4 3 )}\end{array}$ & $\begin{array}{l}\text { Depression } \\
(\mathbf{N = 1 2 7})\end{array}$ & v value \\
\hline Age (SD) & $36.1(5.1)$ & $36(4.9)$ & $37(6.3)$ & $0.04^{*}$ \\
\hline $\begin{array}{l}\text { Smoking } \\
\text { daily }\end{array}$ & $9.8 \%$ & $9 \%$ & $16.5 \%$ & $0.01^{*}$ \\
\hline Alcohol daily & $12.7 \%$ & $12.2 \%$ & $17.3 \%$ & 0.70 \\
\hline Coffee daily & $69.4 \%$ & $69.9 \%$ & $65.4 \%$ & 0.17 \\
\hline Sleeping pills & $5 \%$ & $3 \%$ & $21.3 \%$ & $0.00^{*}$ \\
\hline Exercise & $37.4 \%$ & $38.3 \%$ & $30.7 \%$ & 0.06 \\
\hline
\end{tabular}

Depresion $=$ symptoms of depressions of antidepressives, $\mathrm{SD}=$ Standard Deviation, $\mathrm{p}=$ statistically significant

\section{Discussion}

The point prevalence of depression in this large study, which included 1170 physicians that are mothers, was estimated to be of $10.9 \%$. It was observed that the participants that had depression smoked more and took more sleeping pills that the individuals without depression.

This estimate is similar to what has been reported in the general population in Mexico [8]. However it is lower than what has been observed in a world wide meta-analysis of physicians which estimated that $28.8 \%(95 \% \mathrm{Cl} 25.3-32.5 \%)[9]$.

The finding that smoking and use of sleeping pill is higher in the depressed group is not new. There are many studies that have reported a comorbidity between depression and smoking; and between depression and sleeping disorders. $[15,16]$ In relation to smoking, there are several hypothesis for the correlation included that individuals smoke to alleviate the symptoms of depression, that smoking increases the risk of depression and that there are common genes between addiction and depression. [16] In any case, there are more risks than benefits from smoking, it has been seen that smoking accounts for the reduction of life expectancy associated to mental illness [17].

In relation to sleeping, there is causal relationship between sleep and emotional brain function. There is evidence that nearly all of the patients with depression have one or more sleeping abnormalities [18]. Even though considerable progress has been made in understanding the relationship between sleep and affective brain function, there is much yet to understand. Physicians [18] have access to prescription 
medications and it is common to take sleep pills without a proper diagnoses. A survey of women doctors showed that although almost $50 \%$ believed they had met the criteria for mental illness, they had not sought treatment because they felt they could manage it on their own or were fearful of reporting it to their institutions [19]. It is important to underline that if a person has sleeping and/or mood changes they should contact a specialist to evaluate if a sleeping disorder is causing the depression, or the depression is causing the sleeping disorder. In any case, both disorders should be treated, as they are risk factors for other life threatening diseases.

There is based evidence that physical activity is both a risk factor and a treatment strategy for depression. However, the evidence for efficacy of physical activity has not translated into guidelines, and clinicians have often neglected physical activity as a therapeutic target [20].

Other publications such as a meta-analysis of results from randomized controlled clinical trials concluded that exercise is highly effective as a treatment intervention in depression [21]. What we still need to investigate is if changes in life-style caused depression or depression lead to changes in life-style.

In conclusion, there is evidence that physicians have the same prevalence of depression as the general population. However physicians have access to prescription medications, and they tend to auto-medicate themselves. Drug overdose is the most common suicide method, and is used significantly more often by physicians than the general population [22]. Physicians have a greater risk for suicide, and depression is one of the major risk factors [23]. Compared to the general population, suicide is reportedly $40 \%$ higher in men and $130 \%$ higher in women doctors [24]. Physicians seek professional treatment less frequently and abuse substance more frequently [25]. Physician depression may be under recognized and not adequately treated. Suicidality may be reduced by better detection and adequate treatment of depression and other mental health problems [26].

\section{LIMITATIONS}

A limitation of this study is that that depression was assessed using a self-reported inventory rather than gold-standard diagnostic clinical interviews. While the use of self-report questionnaires is widely accepted in epidemiological studies [17], self-report scales do have their limitations. Items and answer scales differ between the different depression scales and therefore the estimates differ among the different population studied. Another limitation is that we included in our depression definition individuals that were taking antidepressants. Antidepressants are also used to treat obsessive-compulsive disorders, anxiety, or post traumatic stress disorder; therefore there is a chance that some of the participants were taking antidepressants to treat these disorders. These limitations have to be taken into account when comparing with other populations.

\section{Abbreviations}


Confidence Interval (Cl)

Hospital and Anxiety Scale (HAD-s)

Standard Deviation (SD),

\section{Declarations}

\section{Ethics approval and consent to participate}

All participants signed a written informed consent before completing the questionnaire. The questionnaire was reviewed by bioethician Dr. Manuel Isaias Lopez. The procedures performed were in accordance with the ethical standards of the institutional research committee and with the 1964 Helsinki declaration and its later amendments.

\section{Consent for publication}

Not applicable

\section{Availability of data and material}

The datasets used and/or analyzed during the current study are available from the corresponding author on reasonable request.

\section{Competing interests}

SLL works at Novartis Pharmaceuticals. The views presented are not necessarily those of Novartis.

Funding: Not applicable

Authors' contributions: SLL, CADV, LODVP, AHS participated in study design, acquisition and analysis of data and critical revision of the manuscript. KRM participated in analysis of data, drafting interpretation and critical revision of the manuscript.

Acknowledgements: NA

\section{References}

1. Krishnan R. Unipolar depression in adults: Epidemiology, pathogenesis, and neurobiology. Up To Date. 2019. https://www.uptodate.com/contents/unipolar-depression-in-adults-epidemiologypathogenesis-and-neurobiology.

2. Brooks SK, Gerada CCT. Review of literature on the mental health of doctors: are specialist services needed? Journal of Mental Health. 2011;1-11. 
3. Levine RE, Bryant SG.bThe Depressed Physician: a different kind of impairment. Hospital Physician. 2000;(86): 67-73.

4. Robinson GE. Stresses on women physicians:consequences and coping techniques. Depression and Anxiety, 2003; (17), 180-189.

5. Andrade L, Caraveo-Anduaga JJ, Berglund P, Bijil RV, De Graaf R, Vollebergh W, et al. The epidemiology of major depressive episodes: results from de International Consortium of Psychiatric Epidemiology (ICPE) Surveys. Int J Methods Psychiatr Res. 2003;12(1), 3.

6. Malhi GS, Mann JJ. Depression. Lancet. 2018; 392(10161), 2299.

7. Joules D. Depression in resident physicians: a systematic review. Open J Depress. 2014; 3(3), 89-100.

8. Bello M. Diagnosis and prevalence of depression in adult mexican population. Salud Publica de Mexico. 2005; (47), 67-73.

9. Mata DA, Ramos MA, Bansal N, Khan R, Guille C, Di Angelantonio E, et Prevalence of Depression and Depressive Symptoms Among Resident Physicians: A Systematic Review and Meta-analysis. JAMA. 2015; 8;314(22):2373-83

10. Cruz EP. Burnout Syndrome as a risk factor of depression in medical residents. Med Interna Mex. 2006; 22(4), 282-286.

11. Sanchez MJB, Islas CLR, Escobar IV, Rico LES Symptoms of anxiety and depression in residents physicians at high risk or stress. Psiquiatr Biol, 2008;15(5), 147-152.

12. Zigmond AS, Snaith RP. The hospital anxiety and depression scale. Acta Psychiatr Scand. 1983 Jun;67(6):361-70.

13. Bjelland I, Dahl AA.The validity of Hospital Anxiety and Depression Scale. An updated literature review. J Psychosom Res, 2002 (52), 69-77.

14. Desu MM Raghavarao D. Nonparametric statistical methods for complete and censored data. Chapman and Hall 2004

15. Fluharty M, Taylor AE, Grabski M, Munafò MR. The Association of Cigarette Smoking With Depresssion and Anxiety: A Systematic Review. Nicotine Tob Res, 2017; 19(1), 3-13.

16. Murphy MJ, Peterson MJ. Sleep Disturbances in Depression. Sleep Med Clin. 2015; 10(1), 17-23.

17. Royal College of Physicians RcoP, Smoking and Mental Health. 2013 https://www.rcplondon.ac.uk/projects/outputs/smoking-and-mental-health

18. Goldstein AN, Walker MP. The Role of Sleep in emotional brain function. Annu Rev Clin Psychol. 2014 (10), 679-708.

19. Gold KJ, Andrew LB, Goldman EB, Schwenk TL. "I would never want to have a mental health diagnosis on my record": a survey of female physicians on mental health diagnosis, treatment, and reporting. Gen Hosp Psychiatry. 2016;43:51-7.

20. Jacka, Berk. Depression, diet and exercise. MJA Open 2012;1 Suppl 4: 21-23

21. Hoffman BM, Babyak MA, Craighead WE, et al. Exercise and pharmacotherapy in patients with major depression: one-year follow-up of the SMILE study. Psychosom Med 2011; 73: 127-133. 
22. Bailey E, Robinson J, McGorry P. Depression and suicide among medical practitioners in Australia. Intern Med J. 2018;48:254-8.

23. Center C, Davis M, Detre T, Ford D, Hansbrough W, Hendin H, et al. Confronting depression and suicide in physicians: A consensus statement. JAMA. 2003;289:3161-6.

24. Hochberg MS, Berman RS, Kalet AL, Zabar SR, Gillespie C, Pachter HL. The stress of residency: recognizing the signs of depression and suicide in you and your fellow residents. Am J Surg. 2013;205:141-6.

25. Middleton JL. Today I'm grieving a physician suicide. Ann Fam Med. 2008;6:267-9.

26. Glass RM. Awareness about depression: Important for all physicians. JAMA. 2003;289:3169-70. 